\title{
El deporte, proyección, espejo y símbolo cultural: reflexión sobre los deportes de sacrificio y su transmisión de valores en el contexto socioeducativo
}

Roberto Cachán Cruz*

\begin{abstract}
Resumen: Este trabajo analiza y rescata el ritual de sacrificio y se ubica dentro del panorama deportivo contemporáneo en un primer plano. El deporte dentro de los contextos socioculturales predominantes pone en evidencia la conexión entre el dolor corporal y moral, generando importantes valores de entrega y convirtiendo a los deportistas en víctimas. Este artículo presenta una reflexión teórica y crítica de un modelo deportivo emergente y su posible implicación en el campo educativo. Los resultados autorizan la incorporación de valores desde el campo deportivo, constatando que son simbolizados fielmente por la sociedad.
\end{abstract}

Palabras clave: Conducta ceremonial. Cultura. Educación. Deportes.

\section{INTRODUCCIÓN}

Durante lo últimos años en España y en otros muchos países se ha experimentado un considerable aumento y práctica de deportes con gran demanda física, nuevos retos y superaciones sin límites. En sus distintas modalidades (triatlón, maratón, ciclismo de larga distancia, carreras de ultrafondo, alcanzar ocho miles, carreras de montaña en solitario o sin oxígeno, etc,..), pudiéndose catalogar "de sacrificio" por el hecho de soportar dolor y fatiga mental, se han popularizado entre jóvenes y adultos que han practicado siempre deporte, que lo retoman o incluso lo que más sorprende, que sean los

'Departamento Educación Física Secundaria. I.E.S. Fray Diego Tadeo de Ciudad Rodrigo. Salamanca, España. E-mail:rocacruz@hotmail.com 
iniciados los que de pronto la preparen severa y rigurosamente. Esta óptica deportiva se ve amplificada desde los medios de comunicación, en sus redes sociales o por la mitificación de sus participantes. El sociólogo actual es consciente de que el deporte es metáfora de lo social y por lo tanto se hace necesario replantear las relaciones entre los deportistas y las prácticas emergentes. En este marco Sopeña (1976, p. 87) pronuncia que "[...] la categoría general de deporte es la del comportamiento humano". Porque es el sacrificio el que está dejando rastro con nuevos mitos y rituales en la filosofía de hacer deporte. "¿Dónde está el límite?" (Plataforma), "Correr o morir" (Now books) o "La pasión de correr" (Plaza \& Janés) son auténticos tratados que justifican este modelo de sufrimiento. El extraordinario cambio cualitativo del proceso deportivo, tan intenso, provoca y hace que necesite de interés constante de estudio tanto desde el ámbito deportivo como desde la realidad social.

Teóricamente partimos de un posicionamiento del deporte como proceso ritual que reproduce la sociedad. Desde las sociedades más tribales hasta las más industrializadas se ha observado el auge de estos valores como son el reforzamiento corporal o la disciplina, todos ellos con connotaciones de redención. En momentos de crisis se plantean aspectos fundamentales para la sociedad que los sufre y se ponen en marcha mecanismos de defensa. Turner los llamó "dramas sociales" a través de los cuales las tensiones de la estructura social se expresan y por extensión pueden ser los medios por los que se expresen los conflictos sociales. Así, en tanto en cuanto los rituales son expresión de mensajes culturales, permiten modificar su orden social y simultáneamente reforzar sus categorías básicas (BELL, 1997; SCHILLBRACK, 2004). El papel aquí otorgado al ritual es también el de ser una construcción social, con lo que podemos afirmar que el ritual ha estado y estará en todas las culturas, idea que ya definiría Durkheim introduciendo las formas elementales de la vida religiosa, y donde rubrica que "[...] los ritos son representaciones que expresan realidades colectivas, modos de actuar que nacen en el seno de grupos reunidos, y que están destinados a suscitar, mantener o renovar ciertos estados mentales de estos grupos" (DURKHEIM, 1982, p. 38). Otra visión redundada, pero 
trascendental es la que apunta Maffesoli (2000, p. 244) al comentar que "[...] el ritual, al confrontar el sentimiento de pertenencia, [...] permite la existencia del grupo" y es en el deporte donde ese sentir y esa communitas, haga que se ritualice.

La certidumbre es que tales hábitos deportivos no obedecen solo a las lógicas adaptaciones, modas o mercados sino que además responden a cambios fraguados al concepto de sacrificio y que son retenidos por necesidades de la población. Porque el ser humano ha proyectado desde siempre su propio mundo sobre el de los deportes vinculando hecho social con ideología deportiva, incluyendo sus fracasos. Pero lo que parece claro es que el cuerpo, la mente y nuestro comportamiento, forjados en un pasado, se están enfrentando y adaptando a un entorno y desafíos distintos.

El volumen de los estudios de deporte de gran esfuerzo se han centrado en aspectos fisiológicos (ROALDSTAD, 1989; SLEIVERT, 1996); aspectos nutricionales (LINDERMAN; LAUBACH, 2004), psicológicos (BAKER, 2003) y leves acercamientos a estudios sociológicos como por ejemplo aspectos demográficos de los corredores de ultramaratón (HOFFMAN; FOGARD, 2012). Estudios recientes sobre motivación encuentran que la diversión, salud y mantenimiento son los principales motivos para practicar actividad física (RODRÍGUEZ-ROMO; BONET-PASCUAL; GARRIDO-MUÑOZ, 2009). A pesar de todo ello, la sociología deportiva no ha sido productiva en cuanto a la validación de instrumentos para evaluar diferentes variables cognitivas y conductuales que intervienen en la práctica de deportes de sacrificio.

El deporte de sacrificio está comenzando su andadura en la literatura deportiva y no existe una tendencia clara de aplicación práctica. Igualmente, los íntegros datos de las encuestas de hábitos deportivos dirigidas por GARCÍA FERRANDO $(1997,2010)$ ponen de manifiesto las transformaciones que están ocurriendo dentro del sistema deportivo pero no ahonda en otro tipo de motivaciones.

Es la intención de este artículo reflexionar sobre la conciencia de estos deportes, en sus causas y consecuencias, en la posibilidad de transmisión de valores educativos, lo que añade cuerpo a la 
limitada investigación cualitativa, estimulando así nuevas investigaciones. En este sentido debemos apuntar que los sacrificios físicos en el deporte contemporáneo parecen ser proyecciones, representaciones y valores que el cuerpo y la mente han adquirido en nuestra sociedad.

En línea con esa perspectiva, este estudio considera que el deporte construye una serie de creencias, sentimientos y comportamientos que se vivencian en forma de ritual, incitando a una especifica orientación hacia el sacrificio.

\section{EL DEPORTE COMO SACRIFICIO: ÁMBITOS Y DIMENSIONES}

]La mayoría de los hombres "sin-religión" se siguen comportando religiosamente sin saberlo [...] el hombre moderno que se siente y pretende arreligioso dispone aún de toda una mitología camuflada y de numerosos ritualismos degradados. La gran mayoría de los "sin- religión" no se ha liberado de los comportamientos religiosos, de las teologías y mitologías. (ELÍADE, 1967, p. 198)

Las actividades deportivas se han convertido en un símbolo cultural, en una realidad que ha dejado huella en la vida del ser humano y en la sociedad: publicidad, hábitos, costumbres, espectáculos, moda, rituales, mitos, una filosofía de vida, hasta ser interpretado como pilar en el que se apoya con fuerza la historia cultural de nuestro tiempo, y que han dado lugar a distintas planteamientos teóricos que describimos a continuación.

Desde el ámbito de las ciencias del deporte, Diem (1973), Cagigal (1957) y Laín Entralgo (1991) ensalzan el aspecto humano del deporte que, por su total implicación corporal, ritual y espiritual, está llamado a desempeñar cada vez más un profundo rol de garantía humanística. El deporte se hace así sinónimo de conducta humana puesto que ofrece una respuesta múltiple para abordar los modos de interpretar la vida. 
Aunque es comúnmente aceptado por definición que el deporte es inherente a la competición, Laín Entralgo (1991, p. 116) amplía más el significado cuando perfila que "[...] el deporte satisface todas las necesidades de la corporeidad, es manifestación cultural, histórica, del cuerpo y personal, además de ontogénica, filogenética y cosmogénica". Pero, como decía Cagigal (1981, p.180) "[...] todavía nadie ha podido definir con general aceptación en que consiste el deporte: ni como realidad antropocultural, ni como realidad social. Y cada vez va a ser más difícil definirlo". Con esta atrevida cita, ya se constata la complejidad polisémica del término, debido a sus constantes metamorfosis y amplitudes. Sirva la sobresaliente acepción del vocablo de Cagigal (1957, p.17) por su cualidad humanizadora y cultural: "El deporte se ha manifestado siempre donde el hombre ha existido".

Los teóricos encuadrados en la biología explican el deporte como una función meramente biológica, como si fuera uno de los problemas generales de la vida o del desarrollo de los seres vivos. Spencer (1985) defiende, como idea central, que el instinto del juego se explica como una energía biológica.

Los teóricos que estudian el deporte bajo el prisma de la orientación filosófica persiguen comprender la realidad para relacionarlo con el ser y el conocimiento. Heidegger (2003) bajo el prisma del existencialismo, profundiza en la resistencia como fórmula de vida. La resistencia (el trabajo, el esfuerzo) es la variante que necesita el ser en el mundo para mantenerse vivo. Y es que la resistencia ha sido un concepto fecundo en las tareas de toda expresión y creatividad del hombre en el deporte, y no sólo como capacidad básica. En lo concerniente a lo simbólico-ritual, el deporte presenta claros aspectos para compararlos con otras facetas del sistema como separaciones, liminalidad, rituales corporales, status, y que no hacen más que amplificar el estudio del ritual más allá de los contextos etnográficos más tradicionales.

Pues bien, el concepto clásico de entrenamiento, que viene de askesis (ascetismo) se refería a la doctrina y actitud que busca la perfección del hombre mediante la práctica de una vida austera, 
mística y mortificante, al igual que muchas tradiciones religiosas. No es casualidad que una civilización tan interesada en el deporte como la griega prestara atención a la realidad del placer y del dolor. El deportista siente que cuando el dolor se extingue se experimenta una intensa sensación de placer. Desde la psicología utilizan la expresión de experiencia cumbre (Peak Experience); o adicción positiva (BUENO; CAPDEVILLA; FERNÁNDEZ, 2002).

Esta teoría en torno al sacrificio deportivo se ve amplificada desde la perspectiva materialista de Brohm (1975) donde las conductas laborales se aproximan a las deportivas; el deportista participa en los rituales deportivos entendidos éstos como procesos de sufrimiento. Freud podría entender las teorías del juego bajo el punto del psicoanálisis diciendo que las personas tienden a guiar su conducta por impulsos libidinales, placenteros; pero la sociedad moderna crece en torno a la represión de estas tendencias. Brohm (1975) ya apuntaba desde el materialismo histórico que la lógica del cuerpo es la del rendimiento, observando en el deporte y en otras tendencias expresivas de la actualidad, renovadas formas de alienación en cuanto trata de instaurar la ideología del cuerpo como máquina robotizada; en tanto escuela de formación de carácter, formadora de estructuras de personalidad, autoritarias, agresivas, narcisistas y obedientes. El deportista así reprime sus impulsos y si gana y sufre, los glorifica, porque "[...] en el deporte, el modo dominante de las relaciones de los individuos con su propio cuerpo, es el sadomasoquismo, el placer en el esfuerzo doloroso, cuanto más duele, más bueno" (BROHM, 1975, p. 8).

Ejemplos palmarios son los ciclistas coronando altas cimas o el corredor de maratón que llega extenuado que actúan entonces, en la medida de "ritos curativos", recobrando esa identidad perdida.

Desde la arista del hecho religioso, estamos viendo más connotaciones religiosas en las prácticas deportivas. Para ello debemos de resignificar los conceptos sobre rituales religiosos, seculares, festivos o deportivos, pero debemos remarcar que cuando aparece la palabra ritual, ya se reordena por sí solo el concepto, hurtándole el resto de la significación. Balandier (1988, p. 273) nos 
habla del "culto de la religión deportiva". Elíade (1967) o Durkheim (1982) mantienen una postura religiocentrista, estableciendo éste último que la efervescencia colectiva no es más que pasión inducida ritualmente y que configura la base de la religión. Augé (1982) o Van Guennep (2008), trabajando en la dirección de esta revisión, ven los rituales como forma de ser y de actuar, concluyendo que se hacen visibles sentimientos interiores como confesión del pecado, ofrendas o deseo de perdón (ritos expiatorios), representadas por ejemplo en manifestaciones deportivas o peregrinaciones. El Camino de Santiago es pues así un camino para la indulgencia mediante una comunión interior y a través de un esfuerzo físico:

[...] es conocido que para las peregrinaciones católicas existe un cierto número de reglas de santificación previa que, antes de su partida, hacen salir al peregrino del mundo profano y le agregan al mundo sagrado, lo cual se manifiesta exteriormente en el porte de signos especiales (amuletos, rosario, concha, etcétera), y en la conducta del peregrino, por tabúes alimenticios (vigilia) y de otro tipo (sexuales, santuarios, ascetismo temporal). (VAN GENNEP, 2008, p. 254)

En este mismo sentido, conviene respaldar un acercamiento a la trascendencia por medio de la música, el silencio, la meditación, los viajes o los deportes. Mandianes (2010, p. 23) por ejemplo, establece paralelismos entre las peregrinaciones por motivos religiosos con actividades deportivas de hoy, a través de las cuales los seguidores alcanzarían la indulgencia. En esta sociedad en crisis y con claras reminiscencias mitológicas, deporte y sacrificio se refunden a través de las veneraciones, la historia y la memoria. Consecuentemente vemos que hoy la actividad físico-deportiva se tribaliza, surgiendo valores arcaicos, sincretismos religiosos, culto extremo al cuerpo y el deporte de sacrificio (grandes distancias, entrenamientos severos, comunión interior, apoyo mutuo). Hay un intento natural de sacralizarlo todo y el deporte no escapa a esa interpretación. Los gimnasios actúan como fitness espiritual (severas técnicas alimentarias y corporales ancestrales). Videojuegos y anuncios televisivos futbolísticos usan toda una liturgia para llegar al 
consumidor, evocando distinciones y batallas épicas, que en definitiva, como dice Jáuregui $(1978$, p. 9) "[...] se nutren de los profundos sentimientos tribales que en el fondo, animan al hombre de hoy con la misma fuerza que en las épocas más arcaicas".

Otra corriente teórica es la que vincula el deporte y la sociedad tradicional. Esta última está fundada en la existencia de una conciencia colectiva común que se construye a partir de la religión y de sus rituales, y que contribuye a conservar y a recuperar la verdadera naturaleza humana. El ser humano por medio del juego vuelve a su infancia, en donde posiblemente se encuentre la raíz de la propia naturaleza. El deporte entonces, constituye una retroprogresión, término acuñado por Paniker (1983). Es decir, vuelve a nuestros orígenes, a nuestros antepasados, que vitalmente mediatizados por una motricidad básica, descubrieron otras manifestaciones de motricidad. Con todo ello se solicitan nuevas sensaciones y experiencias corporales. Maffesoli (2000) bajo esta perspectiva, considera el deporte como un ritual que transmite los valores tradicionales de la cultura y sirve como metáfora del tribalismo con temas sedimentados en la tradición.

Desde la antropología simbólica, Turner (1980) estudia el reflejo de la cultura en la estructura social. El deporte constituye, como reflejo social, una manifestación ritual y simbólica, viendo así los rituales como disipadores de conflictos sociales y encuentra en los símbolos rituales una polaridad de sentido que favorece la implicación afectiva de los individuos en el proyecto comunitario, como sucede hoy en los deportes de sacrificio.

Por último, la corriente pedagógica (HUIZINGA, 1972; BLANCHARD y CHESKA,1986) señala el juego como elemento fundamental en la educación. Desde el prisma educativo, contribuye a fomentar la solidaridad del grupo y los sentimientos de comunidad viendo los deportes de una naturaleza ritual que, como la religión, ostentan una función integradora. 


\section{DEPORTE DE SACRIFIFICO COMO PRÁCTICA EMERGENTE}

Las muestras deportivas en todas las civilizaciones han seguido un marcado carácter ritual con propósitos mágicos, sacrificiales y religiosos. Aunque hayan pasado por filtros en el sentido de cumplir funciones como el rendimiento, el ocio, la salud o muchas otras, el deporte ha encontrado una fidelidad continua y permanente con el ritual. La danza, las luchas taurómacas cretenses, los antiguos juegos de pelota y muchos otros, forman parte de la cosmovisión propia de los pueblos primitivos.

Una revisión de la literatura en distintas disciplinas del deporte como la sociología, la antropología o la historia nos dan cuenta de ello. Relatos históricos de la exacerbación del deporte como ritual de sacrificio han sido fielmente documentados (VAN GENNEP, 2008). Las pruebas arqueológicas deportivas (TALADOIRE, 2000) y estudios desde la antropología social con GEERTZ (1972), BLANCHARD y CHESCA (1986) o MEDINA y SÁNCHEZ (2003), entre muchos otros, son alegatos que explicitan algún planteamiento de este ideal. La Sociología del deporte encuentra algunos exponentes en BROHM (1975) o PADIGLIONE (1996). Huizinga explicaba el carácter agonal (como sinónimo de competición, sacrificio o representación) de la vida social y eran exaltados a la esfera de lo sagrado (HUIZINGA, 1972, p. 97). Hasta en los deportes más alternativos se cumple esta aceptación. Así, en el surf, que era parte esencial de la cultura hawaiana, los sacerdotes kaunas realizaban sacrificios para pedir a los dioses olas o coraje para los surfistas. Las diversas cuestiones que analizan al deporte dando sentido a la sociedad han sido examinados por ELIAS y DUNNING (1992), AUGÉ (1982) o VERDÚ (1980) no exentas en sus textos de la necesidad del esfuerzo en la construcción de conciencias y representaciones colectivas. Más recientemente, la publicación de MEDINA (2011) o los trabajos de ACUÑA $(2002,2004)$ puede que hayan sentado un antes y un después en el debate sobre el deporte de sacrificio, con aspectos como el mundo mítico, la identidad o la 
tradición. En ellos se reflexiona fugazmente sobre la posible homología que puede existir entre las características del modelo de sociedad moderna y el fondo de la manifestación agonístico-ritual.

Porque la actividad de cubrir grandes distancias no es un fenómeno nuevo. Mientras en los 80 se imponía un modelo deportivo y/o corporal a través del fitness, el aerobic y las artes marciales el comienzo de siglo trajo consigo motivaciones de colectivos por la naturaleza (turismo rural) y la salud (balnearios o pilates). A partir de ahí se comenzó a valorar lo espiritual (yoga). Por el mismo hecho de recuperar actividades o mitos, el cuerpo y la mente así, se sometían a un reaprendizaje corporal y espiritual, un rumbo iniciático. Ya entre los pueblos primitivos y saliendo del grupo, el adolescente vuelve a su familia y a su tribu. Este "aprendizaje simbólico" (LAPASSADE; LHOTELLIER; THIS, 1957, p. 219) y otros rituales de iniciación analizados por CALDERÓN (1999) se pueden comparar hoy, con este tipo de emergentes actividades físicas y corporales: escuchar el cuerpo, rituales de sanación, turismo indígena o heredadas pruebas de esfuerzo ancestrales. Sean Slavin (2003, p. 1) en esta línea considera que el walking body es de hecho la base de la "reinterpretación del yo" que llevan a cabo los peregrinos en el Camino de Santiago. Y todo este regreso sirve de fórmula y se alinea con lo solidario, lo liberador, lo reparador. Incluso en las carreras populares y los nuevos centros de entrenamiento se vivifica el deporte de esta manera.

Se ha establecido entonces una ritualística emergente, un instinto de modelo deportivo para el esfuerzo, de superación y de sufrimiento, aumentando su práctica sobre todo en grupos sedentarios. Entre estas actividades destacamos los deportes de ultrafondo, maratones singulares (de montaña, en condiciones climáticas severas, en desiertos), ascensos a cumbres sin oxígeno, los 100 kilómetros, el triatlón o el Camino de Santiago. Estas disposiciones nos aproximan a una realidad que parece tener respuesta en determinadas poblaciones deportivas: al igual que se recuperaron las termas en sofisticados spas y ciudades termales, se están recuperando las proezas físicas épicas. 
Con todo ello, la práctica de actividades físico-deportivas se dimensiona recreando los valores predominantes de la sociedad postmoderna, sintetizados en la personalización multiforme (prácticas a la carta), la multiplicación de los sistemas de valores, el mito, el tribalismo como medio de integración, la conciencia ecológica, emotiva y corporal.

Hoy en día se denominan runners, ultrafondistas, ultramaratonianos o triatletas y en su corta andadura tienen mucho de legendario, auténticos deportes de agonistas organizados. Éstas y otras carreras han crecido como un fenómeno social imparable junto a iniciativas solidarias, educativas o empresariales. Esta incitación nos lleva a numerosos relatos de sus participantes sobre sacrificio.

En base a todo lo mostrado con anterioridad se pretende llamar la atención desde un enfoque socio-antropológico sobre la respuesta social ante deportes de sacrificio. De igual manera se trata de considerar las motivaciones personales en este tipo de prácticas y las consideraciones acerca de la función educativa.

\section{LAS PRACTICAS DEPORTIVAS DE SACRIFICIO COMO REALIDAD SOCIAL Y COMO PROYECTO DE VIDA}

De acuerdo con los planteamientos anteriores junto a la enorme aceptación, difusión y crecimiento de los deportes de sacrificio, hace que se consideren como una de las más importantes nuevas realidades "morales" en cuanto a significación deportiva. El deporte ha pasado de ser un mero ejercicio físico saludable o espectáculo competitivo, a ser un ritual social y lúdico casi de obligado cumplimiento (ANTOLÍN et al., 2009). Junto a las circunstancias socioculturales contemporáneas descritas, podemos comprender la aparición de fenómenos como la estoica entrega en competiciones deportivas. Ante la falta de investigaciones empíricas sobre las motivaciones en este tipo de prácticas, Llopis y Llopis (2006) encuentran como razón principal por la que los corredores españoles participan en carreras de maratón populares, tiene que ver con el 
placer de correr (disfrute) y la satisfacción con el logro de los objetivos, o los de Barrios y Cardoso (2002) que aluden como principal motivación de la maratón el logro de una meta personal y en mucha menor importancia la aptitud física o el interés por la competición.

Lo que sí se advierte es el afán de competir. Esta dependencia por este tipo de actividades, lo que los deportistas denominan "enganche", ha hecho que en los últimos años el grueso de artículos médicos se haya inclinado hacia la fisiología del ejercicio físico y el rendimiento deportivo así como las respuestas de distintos parámetros bioquímicos (NOAKES, 2003) y algún estudio hacia aspectos psicológicos (LARUMBE et al., 2009). Brevísimos estudios con diversas poblaciones y contextos han reportado la influencia positiva de la personalidad y el rendimiento (SHEARD; GOLBY, 2010), el vínculo entre maratón y crecimiento personal y grado de aceptación (GUINAN; FOLS, 1970) o la formación de los profesionales médicos dentro de las carreras de maratón (EWERT, 2007).

En otra línea, sí se observan estudios comparativos internacionales de ultraresistencia de corte fenomenológico como es el caso de HOLANDER y ACEBEDO (2005) y otros más divulgativos donde se recogen intensas vivencias y relatos de los participantes (AJRAM, 2010; MEDINA, 2011; JORNET, 2011).

Ahora bien, atendiendo a la influencia de la realidad social, podemos advertir que las características de estas disciplinas son tan profundas desde el punto de vista cultural e histórico que responden a lo que los antropólogos denominan un 'comportamiento fósil'; es decir, que tiene sus motivaciones en los orígenes mismos del hombre. El ultrafondista Micah True en el artículo de Mateo (2012) asevera que "[...] correr es una arte antiguo que forma parte de la huella humana", advirtiendo la necesidad de descubrir la práctica (legendaria) para recorrer grandes distancias sin aparente sufrimiento. Los impulsos ancestrales, se hacen evidentes cuando Mc Dougall (2011) analiza la tribu de indios Tarahumaras que son capaces de correr largas distancias, descalzos, sin lesiones y durante toda su vida, hechos todos que facultan una propensión ritual. 
El deporte como ritual (HUIZINGA, 1972; DIEM, 1973; VAN GUENNEP, 2008) y como ritual sacrificial (TURNER; TURNER, 1978) representa la obtención del perdón. Interesante reflexión teórica acerca del fútbol como ritual aparece en el ensayo de Seabra y Rodríguez (1998), Futbol como UM RITUAL, donde los autores comienzan definiéndole y justificándolo como tal, y concluyen, con abundante bibliografía, de qué manera el fútbol es sacralizado, usando numerosos paralelismos. Antropólogos como Bromberger (2000) o Augé (1982) tratan el espectáculo deportivo como una realidad ritual característica de las sociedades modernas y democráticas, hasta el punto de convertirse en una suerte de religión. Turner hablaba de cómo los iniciados y demás participantes son figuras liminales dentro del grupo al que pertenecen y se muestran como un puente entre pasado y futuro. Es el modelo de interacción humana que se caracteriza por vínculos de solidaridad, la vida comunal intensa, la relación igualitaria, la espontaneidad en el trato y el compañerismo (TURNER, 1980), confirmándose la creencia popular en el caso de corredores de ultrafondo. Es por ello que se le puede atribuir cierto componente ritual ya que por sí mismo contribuye a la percepción de bienestar de los participantes, en la línea de Maffesoli (2009, p. 57) cuando dice "conceder importancia al sentido estético de las cosas, participar en las múltiples histerias (deportivas, musicales, religiosas, políticas) que ritman la vida social La presencia mediática y los mitos vienen a significar un fenómeno de re-"tribalización" de la vida social".

Con todo ello podemos reconocer que nos encontramos con un colectivo de deportistas que piensa que se está complementado una personalidad deportiva con un proyecto de vida, promoviéndose en un principio casi canónico, el deber de cambiar. Se recuperan así valores perdidos tales como la entrega y la humildad. No falta nunca en estas diplomacias el deportista héroe que proclama este espíritu ganador en el sentido de los valores que puede otorgar como santidad moral, sacrificio, férrea disciplina ante la falta de cultura del esfuerzo, sobre todo en edades escolares. Y eso influye activamente en la conducta de quien lo lee, lo sigue o lo profesa. Este eje semántico instructivo no viene de ahora ya que según muestra Moscoso (2005), 
al atleta-soldado de las polis griegas ya se le conferían atributos guerreros y de prestigio político y social. Es decir, el deportista héroe transmitía conciencia cívica en un momento en que era necesario reclutar soldados y guerreros a la vez que exaltar sus virtudes. La aproximación de estas concepciones al lenguaje deportivo se hace oportuna y necesaria sobre todo a un público joven. Así por ejemplo, hay quien verifica una educación en valores a través de la rivalidad de un derbi clásico en el fútbol español (GINESTA, 2007).

Podemos ver que el papel que juega la sociedad se acerca a la acción sufriente y personal de los deportistas. Son muchas las alusiones al esfuerzo personal, como si se tratase de una especie de lucha individual contra unas condiciones personales y sociales, siendo relevantes las consecuencias de compromiso. Así, fácilmente identificamos que los deportes de sacrificio presentan una enorme eficacia ritual y simbólica y que ante la falta de valores, son aprehendidos por la sociedad.

\section{EL DEPORTE DE SACRIFCIO Y CONSIDERACIONES PEDAGÓGICAS}

Estos deportes se encuentran en un marco general de transformaciones constantes, situación que demanda nuevos mecanismos en la formación educativa, con el objeto de incorporar estrategias de enseñanza-aprendizaje. En lo que se refiere a los contenidos en el currículum de educación física escolar en España, únicamente la reciente publicación de 2012 por parte del Consejo Superior de Deportes del plan formativo del triatlón dentro de las enseñanzas de régimen especial, así lo atestiguan. Cabe reseñar también la visión saludable y didáctica de la práctica del triatlón dentro de la educación física (HIDALGO, 2002) o las aportaciones del triatlón en el aprendizaje deportivo (FAULL; CROPLEY, 2009).

En los exigentes entrenamientos, que actúan como verdaderos cultos de sacrificio, existe una aplicación directa que intenta condescender en los esquemas mentales hacia los alumnosdeportistas que se debería aplicar a la realidad con la que se van a encontrar. Entonces el éxito del alumno ahora depende en buena 
medida, de su manera de hacer deporte, donde las funciones deportivas son las funciones sociales. El deporte de esfuerzo se tendría que vivir como medio de personalización y de personificación, como medio de orientación humana, como una filosofía de vivir, como paradigma moralizante. Considerando estos atributos, el argumento que se descubre es que en este tipo de actividades y en su relativa corta historia es que está obrando de igual manera como medio deportivo que cultural.

Por otro lado, debemos referenciar el papel de los medios de comunicación porque la temática deportiva en éstos, no sólo ocupa, sojuzga y profesa. El fenómeno deportivo brinda en sus quehaceres, modos y prácticas, importantes elementos teóricos para la reflexión como fuerza enculturadora. Es el relato escrito el que contribuye a reafirmar que el lector, sea seguidor o no, mantenga una identificación con el deporte y con el deportista y por ende, con la cultura de esfuerzo, porque no sólo se refleja lo que ocurre en el mundo social sino que lo acentúa y lo redefine.

Una de las funciones de los media más valorada en educación es, precisamente, la de ser facilitadores del conocimiento cotidiano (DE ARIAS, 2005).

Dentro de esta tesitura, el análisis de noticias y sobre todo los discursos de los participantes (de notoria carga moral) constituyen un instrumento valedero para articular patrones de conducta, así como valores que fomentan entre otros, la memoria comunitaria y valores cívico-moralistas. Esto nos lleva a plantear en el sentido de los valores que puede otorgar como sacrificio o férrea disciplina ya que hemos observado que la representación que hacen los medios de comunicación sobre el deporte incide en los imaginarios que crean es sus audiencias (GINESTA, 2007), lo que demanda una preocupación por proponer espacios de interacción cultural vinculados con la educación; dicho de otro modo, el hecho de identificar en la prensa las analogías de esfuerzo nos hace pensar en una reformulación de contenidos, conjugando mecanismos cognitivos y educativos. Además, este lenguaje otorga al deporte el papel de reconductor de sentido, porque en palabras de Sánchez y Sánchez 
(2001), "[...] es un aparato semántico básico en la transmisión de valores", más si cabe en un contexto de crisis social, política, cultural e ideológica.

\section{ConsiderACIONES FINALES}

El deporte de sacrificio es una manifestación de nuestro tiempo donde las situaciones personales parecen estar por encima de las deportivas a la hora de fijar sus motivaciones, generando además sólidas expectativas en el terreno educativo, sobre todo a través de los medios de comunicación. Muchos países están repletos de actividades de gran esfuerzo, hecho que está reforzando la identidad local, repercutiendo en la imagen saludable de la zona, creando mercados y una filosofía de vivir. Incluso la realidad educativa se debería beneficiar de ello por su imaginaria pedagogía de esfuerzo.

En los deportes de sacrificio, podemos acreditar que el reto personal y la actitud ante la vida transmiten unos valores que en este caso -y como respuesta a una crisis económica, cultural e ideológica, van ajustadas al origen y naturaleza propio del hombre. Las prácticas deportivas de gran esfuerzo físico se convierten así en una suerte de evasión simbólica y consolidan un vínculo que reproduce fielmente lo social.

Porque podemos advertir que estas prácticas se quieren presentar como una moral necesitada, como respuesta a un estado general de conciencia que clama por la vuelta de valores perdidos: el esfuerzo constante, la perseverancia, la disciplina y el sacrificio como mecanismos de excelencia. Las bondades terapéuticas del esfuerzo deportivo parecen ser una solución esperanzadora y catártica contemporánea a al vez que un modelo educativo alternativo, que alumbran el sentido pleno de la vida humana.

Entre las futuras investigaciones que se desprenden de nuestro estudio incluimos la necesidad de un mayor tiempo de aplicación (otros deportes y en otros contextos), con una muestra de sujetos y 
una mayor sistematización del proceso de evaluación, además de constatar con rigor estadístico si la problemática social influye para emprenderse a ese tipo de pruebas deportivas. 


\begin{abstract}
Esporte, símbolo espelho de projeção e cultural: reflexão sobre esportes de sacrifício e de transmissão de valores no contexto social e educacional

Resumo: Este artigo analisa e recupera todo um ritual de sacrifício e situa-o num primeiro plano dentro do cenário esportivo atual. Num contexto sociocultural predominante o esporte evidencia a ligação existente entre a dor física e moral, incorpora valores de entrega e faz dos desportistas vítimas. Este artigo reflete de forma teórico-crítico sobre uma modalidade esportiva emergente e refere a sua possível conexão com o modelo educativo. Os resultados oferecem incorporar valores ao campo esportivo, provando que são adotados de forma simbólica pela sociedade.

Palavras-chave: Comportamento ritualístico. Cultura. Educação. Esportes.
\end{abstract}

\title{
Sport, projection, mirror and cultural symbol: reflection on endurance sports of values in social and educational context \\ Abstract: This article analyses and recovers the ritual of sacrifice and it's embedded within the current sporting spectrum in a privileged position. The sport within the prevailing sociocultural contexts shows the connection between physical and moral pain, causing significant levels of effort and turning athletes into victims. This article features a theoretical and critical reflection on an emerging sports model and its potential involvement in education. The results allow the inclusion of sport-based values, stating they are faithfully supported by society. \\ Keywords: Ceremonial behavior. Culture. Education. Sports.
}

\section{REFERENCIAS}

ACUÑA Delgado, Ángel. ¡No hay límites! 101 km en 24 horas. Una interpretación antropológica. Apunts, Barcelona, n. 67, p. 88-96, 2002.

ACUÑA Delgado, Ángel. La carrera rarámuri como metáfora de resistencia cultural. Apunts, Barcelona, n. 75, p. 20-24, 2004.

AJRAM, Josef. ¿Dónde está el límite?. Barcelona: Plataforma, 2010.

ANTOLÍN, Virginia; DE LA GÁNDARA, Jesús; GARCÍA, Isabel; MARTíN, Alicia. Adicción al deporte: ¿moda postmoderna o problema sociosanitario?. Norte de Salud Mental, Bilbao, n. 34, p.15-22, 2009. 
AUGÉ, Marc. Lugares de deporte, lugares de rituales. In: BARREAU, Jean Jacques; MORNE, Jean Jacques. Epistemología y Antropología del deporte. Madrid: Alianza, 1982.

AUGÉ, Marc. "Un sport ou un rituel?". Manière de voir. Le Monde diplomatique, Football et passions politiques, Paris, n. 9, p. 74-78, 1998.

BAKER, Joseph; DEAKIN, Janice, COTE, J.. Predicting performance in ultraendurance triathletes from training indices. Paper presented at the NASPSPA Conference, Savannah, Ga. Journal of Sport and Exercise Psychology, v. 25(Supl.), p. S24, 2003.

BALANDIER, Georges. Modernidad y poder. Madrid: Júcar, 1988.

BARRIOS, René; CARDOSO, Laura. Motivación para competir en corredores populares cubanos. Lecturas: Educación física y deportes, Buenos Aires, n. 47, p. 1-2, abr. 2002. . Acceso en: www.efdeportes.com/efd47/motiv.htm.

BARTHES, Roland. Eléments de sémiologie. Communications, Paris, n. 4, 1964.

BELL, Catherine. Ritual Perspectives and Dimensions. Oxford: University Press, 1997.

BLANCHARD, Kendall; CHESCA, Alyce. Antropología del deporte. Barcelona: Bellaterra, 1986.

BROMBERGER, Christian. El fútbol como visión del mundo y como ritual. In: ROQUE, Maria Angels (ed.), Nueva antropología de las sociedades mediterráneas. Icaria-Antrazyt, Barcelona, 2000.

BUENO, Javier; CAPDEVILLA, Lluís; FERNÁNDEZ-CASTRO, Jordi. Sufrimiento competitivo y rendimiento en deportes de resistencia. Revista de Psicología del Deporte, Barcelona, v. 11, n. 2, p. 209-226, 2002.

BROHM, Jean-Marie. Tesis sobre el deporte. Quel Corps?, Paris, n. 1, p. 52, 1975.

CAGIGAL, José María. Hombres y deporte. Madrid: F.C.E, 1957.

CAGIGAL, José María. ¡Oh deporte!: Anatomía de un gigante. Valladolid: Miñón, 1981.

CALDERÓN, Eduardo. Deportes y límite. Madrid: Anaya, 1999.

DE ARIAS, María Eugenia. Sobre el para qué de la comunicación social: aproximación a la teoría de la mediación. Anuario Ininco, Caracas, v. 17, n. 2, p. 375-395, 2005.

DENZIN, Norman; LINCOLN, Yvonna. Handbook of qualitative research. London: Sage, 2000.

DIEM, Carl. Orígenes rituales. Citius, Altius, Fortius, v.15, n. 1/4, 1973. 
DURKHEIM, Emile. Las formas elementales de la vida religiosa. Madrid: Akal, 1982.

ELÍADE, Mircea. Lo sagrado y lo profano. Madrid: Guadarrama, 1967.

ELÍAS, Norbert; DUNNING, Eric. Deporte y ocio en el proceso de civilización. Madrid: F.C.E, 1992.

EWERT, Greg. Marathon Race Medical Administration. Sport Medicine, Chicago, v. 37, n. 4-5, p. 428-430, 2007.

FAULL, Andrea; CROPLEY Brendand. Reflective learning in sport: a case study of a senior level triathlete. Reflective Practique, London, v. 10, n. 13, p. 325-339, 2009.

GARCÍA FERRANDO, Manuel. Los españoles y el deporte (1980-1995): un análisis sociológico sobre comportamientos, actitudes y valores. Madrid: Consejo Superior de Deportes, 1997.

GARCÍA FERRANDO, Manuel. Encuesta sobre los hábitos deportivos en España. Madrid: Ministerio de Educación, Cultura y Deporte. Consejo Superior Deportes, 2010.

GINESTA PORTET, Xavier. Los valores en el deporte: una experiencia educativa a través del Barça-Madrid. Comunicar. Revista científica de comunicación y educación, Andalucía ,v. 28, p. 148-156, 2007.

GUINAN, James; FOULDS, Melvin. Marathon group: Facilitator of personal growth?. Journal of Counseling Psychology, Arizona, v. 2, n. 17, p. 145-149, 1970.

HEIDEGGER, Martin. ¿Qué es metafísica?. Sevilla: Renacimiento, 2003.

HIDALGO SANTOS, Pere. El triatlón: competición, salud y educación. Tándem, Barcelona, n. 8, p. 83-104, 2002.

HOFFMAN, Martin; Fogard, Kevin. Demographic characteristics of 161-km ultramarathon runners. Research in Sports Medicine, London, n. 20, p. 59-69, 2012.

HOLLANDE, Daniel; ACEBEDO, Edmund. Successful English Channel swimming: the peak experience. The sport psychologist, London, v. 14, n. 1, p. 1-16, 2005.

HUIZINGA, Jan. Homo Ludens. Madrid: Alianza, 1972.

JORNET, Kilian. Correr o morir. Barcelona: Now Books, 2011.

JÁUREGUI, Jose Antonio. Las reglas del juego. Madrid: Espasa-Calpe, 1978.

LAÍN ENTRALGO, Pedro. El Cuerpo humano. Madrid: Espasa-Calpe, 1991.

LAPASSADE, Georges; LHOTELLIER, Alexandre; THIS, Bernard. Le psychosociologue dans la cité. Paris: EPI, 1957. 
LARUMBE, Eneko; PÉREZ-LLANTADA, Carmen; LÓPEZ, Andrés. Características del estado de los corredores populares de maratón. Revista de Psicología del deporte, Barcelona , v. 18, n. 2, p. 151-163, 2009.

LLOPIS, David; LLOPIS, Ramón. Razones para participar en carreras de resistencia: un estudio con corredores aficionados. Cultura, ciencia y deporte. Universidad Católica de San Antonio de Murcia, Murcia, v. 2, n. 4, p.33-40, 2006.

MACDOUGALL, Christopher. Nacidos para correr: la historia de una tribu oculta, un grupo de superatletas y la mayor carrera de la historia. Barcelona: Debate, 2011.

MAFFESOLI, Michell. El tiempo de las tribus. Barcelona: Icaria, 2000.

MAFFESOLI, Michell. El instante eterno, el retorno de lo trágico en las sociedades postmodernas. Barcelona: Paidós, 2001.

MAFFESOLI, Michell. Iconologías: nuestras idolatrías. Barcelona: Península, 2009.

MANDIANES, Manuel. Año santo compostelano. El Mundo, Madrid, p. 1-4, 19 de feb. 2010.

MEDINA, Francisco. La Pasión de correr. Barcelona: Plaza \& Janés, 2011.

MEDINA, Francisco; SÁNCHEZ, Ricardo. Culturas en juego: ensayos de Antropología del deporte en España. Barcelona: Icaria, 2003.

MOSCOSO, David. La construcción social y cultural del liderazgo en el deporte. Apunts, Barcelona , v. 8, n. 79, p. 8, 2005.

NOAKES, Timothy. Lore of running. Oxford: University Press, 2003.

PADIGLIONE, Vicente. Antropología del deporte y del ocio, In: PRAT, J.; MARTÍNEZ, A. (eds.). Ensayos de antropología cultural: Homenaje a Claudio EstevaFabregat. Barcelona: Ariel, 1996. p. 399-404.

MATEO, Juan José. El límite soy yo. El País Semanal, Madrid, p. 23-26, 18 de nov. 2012.

PANIKER, Salvador. Ensayos retroprogresivos. Kairós: Barcelona, 1983.

ROALDSTAD, Melinda. Physiologic testing of the ultraendurance triathlete. Medicine and Science in Sports and Exercise, Massachusetts v. 5, n. 21, p. 200-204, 1989.

RODRÍGUEZ-ROMO, Gabriel; BONED-PASCUAL, Carlos; GARRIDO-MUÑOZ, María. Motivos y barreras para hacer ejercicio y practicar deportes en Madrid. Revista Panamericana de Salud Publica, Washington, v. 26, n. 3, p. 244-254, 2009.

SÁNCHEZ, Ricardo; SÁNCHEZ, Jorge. "Culturas deportivas y valores sociales: una aproximación a la dimensión social del deporte". Apunts, Barcelona, n. 64, p. 33, 2001. 
SCHILBRACK, Kevin. Introduction. In: SCHILBRACK, K. (ed.). Thinking through Rituals: Philosophical Perspectives. Londres: Routledge, 2004. p. 1-30.

SEABRA, Daniel; RODRÍGUEZ, Joana. Futebol como um ritual. Antropológicas, Oporto, n. 2, p. 15-34, 1 jun. 1998.

SHEARD, Michael; GOLBY, Jim. Personality hardiness differentiates elite-level sport performance. International Journal of Sport \& Exercise Psychology, Ohio, n. 8, p. 160-169, 2010.

SLAVIN, Sean. Walking as Spiritual Practice: The Pilgrimage to Santiago de Compostela, Body and Society, London, v. 9, n. 3, p.1, 2003.

SLEIVERT, Gordon; ROWLANDS, David. Physical and physiological factors associated with success in the triathlon. Sports Medicine, Chicago, n. 22, p. 818, 1996.

SOPEÑA, Alberto. Deporte y personalidad creadora. Cátedra Universitaria de tema deportivo y cultural. Universidad Pontificia de Salamanca, 1976.

SPENCER, Herbert. Principios de Psicología. Madrid: Espasa-Calpe, 1985.

TALADOIRE, Eric. El juego de pelota mesoamericana. Arqueología Mexicana, México, v. 8, n. 44, p. 20-27, 2000.

TURNER, Victor; TURNER, Edith. Image and Pilgrimage in Christian Culture. Anthropological Perspectives. Nueva York: Columbia University, 1978.

TURNER, Victor. La selva de los símbolos. Madrid: Siglo XXI, 1980.

VAN GENNEP, Arnold. Los ritos de paso. Madrid: Alianza, 2008. Traducción de Juan Aranzadi, original en francés Les rites de passage, [1909].

VERDÚ, Vicente. El fútbol, mitos, ritos y símbolos. Madrid: Alianza, 1980.

Endereço para correspondencia:

Roberto Cachán Cruz

C/Juan II $21^{\circ} \mathrm{F}$

24003 León

España

Recebido em: 28.12.2012

Aprovado em: 27.04.2013 